\title{
A prospective study of renal disease in patients with early rheumatoid arthritis
}

\author{
Y Koseki, C Terai, M Moriguchi, M Uesato, N Kamatani
}

Abstract

Objectives-This prospective study was designed to clarify the frequency, causes, and clinical course of renal disease in patients with early rheumatoid arthritis (RA).

Methods-235 patients (185 women, mean age 49.4 years) with early RA of less than one one year's duration wer assessed monthly. Proteinuria was defined as a positive dipstick result and microscopic haematuria was defined as the presence of $\geqslant 5$ red blood cells per high power field. Urinary abnormalities lasting three months or longer were defined as persistent abnormalities.

Results-At entry, 40 patients exhibited Results-At entry, 40 patients exhibited creatinine concentration, and none had proteinuria. During the observation period (average 42 months), persistent haematuria was found in 43 , persistent proteinuria in 17 , and a raised serum creatinine concentration in 14 patients. Persistent proteinuria was caused by drugs in 14 of 17 patients and disappeared in most cases. Risk factors for drug induced proteinuria included a raised $C$ reactive protein and erythrocyte sedimentation rate and age over 50 at entry. Drugs resulted in a raised serum creatinine concentration in eight of 14 patients. The incidence of haematuria at entry did not differ among patients who had been treated with non-steroidal antitreated with non-steroidal anti-
inflammatory drugs, disease modifying antirheumatic drugs, or no drugs. In some patients with isolated haematuria, the haematuria appeared when the activity of RA was high and resolved when it was low. Conclusions-This study suggests that a raised serum creatinine concentration or persistent proteinuria in patients with early RA is predominantly drug related whereas, in contrast, isolated haematuria is more directly associated with the activity of the disease process.

(Ann Rheum Dis 2001;60:327-331)

Y Kosek

C Terai

M Moriguchi

M Uesato

N Kamatani

Correspondence to:

Dr C Terai, Institute of

Rheumatology, Tokyo

Women's Medical Universi

162-0054, Japan

chihirot@ior.twnu.ac.jp

Accepted 18 August 2000 rheumatoid vasculitis, other complicati eases, and RA itself. ${ }^{16}$ In fact, renal disease was reported to occur more commonly in RA than in other collagen diseases, with the exception of systemic lupus erythematosus and vasculitis. ${ }^{1}$ Indeed, end stage renal failure was a common cause of death of patients with RA until dialyis became readily available. ${ }^{78}$ Renal disease in RA, however, has not received much study.

The prognosis of patients with RA showing renal disease varies greatly. For instance, poteinuria induced by gold or sulphydryl proteinu is thought to disappear without leaving any sequela after the drugs are topped. ${ }^{9}{ }^{10}$ Patients with haematuria associated with the pathological finding of mesangial glomerulonephritis were also shown to have a favourable prognosis. ${ }^{11}{ }^{12}$ In contrast, the prognosis of patients with AA amyloidosis or rapidly progressive cresc important to determine accurately the nature of the renal lesion in the kidneys of patients with abnormal rena findings.

In patients with advanced RA the cause of renal damage is often difficult to define because of the coexistence of multiple possible causes. Boers et al found pathological findings, including benign nephrosclerosis ( $90 \%)$, tubulointerstitial change $(41 \%)$, glomerular change $(43 \%)$, renal amyloidosis $(11 \%)$, and renal vasculitis $(6 \%)$ in necropsy specimens from patients with $\mathrm{RA}$ among whom the percentage of patients with clinically recognised renal damage before death was $52 \%{ }^{1}$ Thus heterogeneous renal lesions may complicate advanced RA even if hey are not clinically apparent.

In the early stage of RA, however, renal lesions such as amyloidosis, vasculitis, and chronic interstitial change induced by drug are rare. Therefore, data from patients with early RA are more suitable for the analysis of the incidence of drug induced renal damage and haematuria caused by mesangial glomeruIn this paper we describe the results of a prospective cohort study that was undertaken to determine the incidence of renal disorders in patients with early RA and to clarify its cause and outcome.

\section{Patients and methods}

PATIENTS

Two hundred and thirty five patients with RA who attended the outpatient clinic of the Institute of Rheumatology, Tokyo Women's Medical University, between 1991 and 1997 within one year from the onset of RA, were enrolled. On enrolment, a careful drug history was obtained. Thereafter, they were examined monthly by rheumatologists and blood samples monthy were withdrawn for blood cell count, bloo

chemistry, erythrocyte sedimentation rate 
Table 1 Baseline clinical characteristics of the 235 patients with early rheumatoid arthritis enrolled
study. Data are mean (SD) or number (\%)

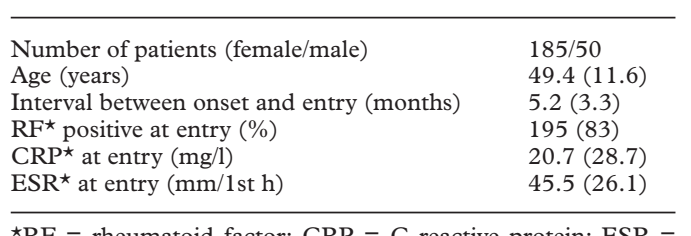

${ }^{\mathrm{RF}}=$ rheumatoid factor; $\mathrm{CRP}=\mathrm{C}$ reactive protein; $\mathrm{ESR}=$ erythrocyte sedimentation rate.

Table 2 Occurrence of various renal abnormalities in 235 patients with early rh during the follow up period, and in controls

\begin{tabular}{|c|c|c|c|}
\hline & $\begin{array}{l}\text { Proteinuria } \\
(\%)\end{array}$ & $\begin{array}{l}\text { Haematuria } \\
(\%)\end{array}$ & $\begin{array}{l}R C r t \\
(\%))^{\circ}\end{array}$ \\
\hline $\begin{array}{l}\text { Early } \mathrm{RA}^{\star}(\mathrm{n}=235) \\
\text { At entry }\end{array}$ & & & \\
\hline \multicolumn{4}{|c|}{$\begin{array}{l}\text { At entry } \\
\text { During observation period }\end{array}$} \\
\hline Persistent & $17(7)$ & $43(18)$ & \\
\hline Intermittent & & $56(24)$ & \\
\hline $\begin{array}{l}\text { Total } \\
\mathrm{p} \text { Valuet }\end{array}$ & $\begin{array}{l}23(10) \\
<0.005\end{array}$ & $\begin{array}{l}99(42) \\
<0.0001\end{array}$ & $\begin{array}{l}14(6) \\
<0.05\end{array}$ \\
\hline \multicolumn{4}{|l|}{ Controls $^{\star}(n=100)$} \\
\hline During 42 months & & & \\
\hline Persistent & $1(1)$ & $10(10)$ & \\
\hline Intermittent & $0(0)$ & $7(7)$ & \\
\hline Total & $1(1)$ & $17(17)$ & $1(1)$ \\
\hline
\end{tabular}

$\star$ The study of patients with early RA was prospective and that of

tp Value for the difference of frequency of renal abnormalities between early RA and control.

$\neq \mathrm{RCr}=$ raised serum creatinine concentration

(ESR), and C reactive protein (CRP) measurement. Patients who dropped out within six months of enrolment were excluded from the analysis. One hundred patients with nonsystemic diseases like osteoarthritis, lumbago, and traun jeriods 作 age and sex matched control group and their records were reviewed for evaluation of renal disease.

LABORATORY EVALUATION OF RENAL DISEASE Proteinuria was assessed by Ames dipstick test (Bayer-Sankyo, Tokyo, Japan) and $1+$ or greater (albumin $>250 \mathrm{mg} / \mathrm{l}$ ) was interpreted as abnormal. Microscopic haematuria was screened by the dipstick test. A positive dipstick test was followed by microscopic examination of the urine sediment, with haematuria being defined as the presence of $\geqslant 5$ red blood cells per high power field. Urinary red bloodicen wer defittent when they lasted for less than three months but persistent when they lasted for three months or more. Urinary abnormalities of less than three months' duration were excluded from the evaluation. Urine samples were not collected during or just after menstruation. A raised serum creatinine concentration (RCr) was defined as a serum creatinine concentration (Cr) exceeding the upper limit of the normal range $(>115 \mu \mathrm{mol} / 1(1.3 \mathrm{mg} / \mathrm{dl})$ for men and $>97 \mu \mathrm{mol} / 1(1.1 \mathrm{mg} / \mathrm{dl})$ for women $)$ or when the Cr increased by $\geqslant 26 \mu \mathrm{mol} / 1(0.3 \mathrm{mg} / \mathrm{dl})$ over the value recorded at entry. All patients with isolated haematuria underwent either intravenous urography or abdominal ultrasonography to exclude anatomical disorders of the
Table 3 Causes of proteinuria

\begin{tabular}{ll}
\hline Cause & No of patients \\
\hline Persistent proteinuria $(\mathrm{n}=17)$ & \\
Drug induced & \\
by DMARDs & \\
by NSAIDs & \\
Floating kidney & 13 (14 times) \\
Chronic UTI & 1 (2 times) \\
Unknown & 1 \\
Intermittent proteinuria (n=6) & 1 \\
Hypertension? & 1 \\
Unknown & 1 \\
\hline
\end{tabular}

disease modifying antinheumatic drugs; NSAID infection.

genitourinary tract. Drug induced renal damage was defined as renal damage that developed after the drug was started and which disappeared when the drug was stopped.

STATISTICAL ANALYSIS

The data obtained were analysed by $\chi^{2}$ test, Fisher's exact probability test, two tailed Student's $t$ test, Wilcoxon's test, and the nonparametric Mann-Whitney U test. p Values less than 0.05 were considered significant.

\section{Results}

BASELINE CLINICAL CHARACTERISTICS OF THE PATIENTS

At entry, 235 patients fulfilled the criteria of classical, definite, or probable RA according to the 1958 classification criteria established by the American Rheumatism Association. ${ }^{14}$ At the end of the study, however, all the patients the end of the study, however, all the patients
fulfilled the 1987 criteria for the classification fulfilled the 1987 criteria for the classification
of RA. ${ }^{15}$ Table 1 summarises the baseline clinical characteristics of the patients. The average interval between the onset of RA and enrolment was 5.2 months (range 1-12).

OCCURRENCE OF RENAL DISEASE

The patients were followed up for six to 77 months (mean 42 months). During the observation period non-steroidal anti-inflammatory drugs (NSAIDs) and disease modifying antirheumatic drugs (DMARDs) were given to $100 \%$ and $95.2 \%$ of the patients respectively. Table 2 shows the percentages of patients with renal abnormalities at entry and during the folow up period. No episodes of macroscopic haematuria were recorded. The percentage of patients with proteinuria, haematuria and/or $\mathrm{RCr}$, increased during the course of the study (table 2). Haematuria was intermittent in $56 / 99(57 \%)$ patients, whereas proteinuria was persistent in $17 / 23(74 \%)$ cases (table 2). These renal abnormalities in patients with early A were significantly more common than in he control group.

CAUSE OF PROTEINURIA

Drugs were the cause of persistent proteinuria (PP) in most patients, whereas the causes of intermittent proteinuria were less clear (table 3).

OCCURRENCE AND OUTCOME OF DRUG INDUCED

The total number of times each drug was used was recorded and compared with the number of episodes of the drug induced PP for each 
Table 4 Occurrence of drug induced persistent proteinuria (PP)

\begin{tabular}{|c|c|c|c|}
\hline Drug & $\begin{array}{l}\text { No of times drug } \\
\text { was used }\end{array}$ & $\begin{array}{l}\text { Episodes of drug } \\
\text { induced PP }\end{array}$ & $\begin{array}{l}\text { Occurrence } \\
P P(\%)\end{array}$ \\
\hline \multicolumn{4}{|l|}{$\overline{\text { DMARDs}^{\star}}$} \\
\hline Auranofin & 59 & 1 & 1.7 \\
\hline Gold thiomalate & 52 & 2 & 3.8 \\
\hline Bucillamine & 105 & 4 & 3.8 \\
\hline D-Penicillamine & 100 & 5 & 5.0 \\
\hline Sulfasalazine & 91 & 1 & 1.1 \\
\hline Methotrexate & 57 & 0 & 0.0 \\
\hline Gold thiomalate + bucillamine & $\mathrm{NC}^{\star}$ & 1 & - \\
\hline \multicolumn{4}{|l|}{ NSAIDs* ${ }^{\star}$} \\
\hline Diclofenac $\mathrm{Na}$ & 126 & 2 & 1.6 \\
\hline \multicolumn{4}{|c|}{$\begin{array}{l}\text { *DMARDs = disease modifying antirheumatic drugs; NSAIDs = non-steroidal anti-inflammato } \\
\text { drugs; } \text { NC }=\text { not clear. }\end{array}$} \\
\hline \multicolumn{4}{|c|}{$\begin{array}{l}\text { Table } 5 \text { Risk factors of drug induced persistent proteinuria (PP). Data are given as mear } \\
\text { (SD) or number (\%) }\end{array}$} \\
\hline & $\begin{array}{l}\text { Patients with drug } \\
\text { induced } P P(n=14)\end{array}$ & $\begin{array}{l}\text { Patients without } \\
\text { proteinuria } \\
(n=212)\end{array}$ & $p$ Value \\
\hline \multicolumn{4}{|l|}{ At entry } \\
\hline $\mathrm{CRP \dagger}(\mathrm{mg} / \mathrm{l})$ & $53.4(50.0)$ & $17.7(24.5)$ & $<0.001^{\star}$ \\
\hline $\mathrm{ESR}+(\mathrm{mm} / 1 \mathrm{st} \mathrm{h})$ & $60.2(22.0)$ & $43.1(24.6)$ & $<0.05^{\star}$ \\
\hline $\mathrm{RF}^{\star}$ positive $(\mathrm{No}(\%))$ & $11(79)$ & $179(84)$ & NSt \\
\hline $\operatorname{Sex}(\mathrm{F} / \mathrm{M})$ & $12 / 2$ & $164 / 48$ & \\
\hline Age $\geqslant 50($ No $(\%))$ & $11(79)$ & $111(52)$ & $<0.05$ \\
\hline Haematuria at the entry (No (\%)) & $4(29)$ & $35(17)$ & NS \\
\hline \multicolumn{4}{|l|}{ During observation period } \\
\hline No of DMARDs† used & $2.57(1.16)$ & $2.07(1.50)$ & NS \\
\hline No of gold and $\mathrm{SH} \dagger$ compounds used & $1.50(0.65)$ & $1.32(0.90)$ & \\
\hline Persistent haematuria (No (\%)) & $8(57)$ & $30(14)$ & $<0.0005$ \\
\hline
\end{tabular}

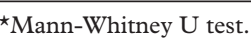

$\mathrm{CRP}=\mathrm{C}$ reactive protein; $\mathrm{ESR}=$ erythrocyte sedimentation rate; $\mathrm{RF}=$ rheumatoid factor DMARDs = disease modifying antirheumatic drugs; $\mathrm{SH}=$ sulphydryl; NS = not significant.

Table 6 Causes and course of raised creatinine concentration (RCr) in the study patients

\begin{tabular}{|c|c|c|}
\hline Cause & No & Course of $R C r$ \\
\hline \multicolumn{3}{|l|}{ At entry $(n=2)$} \\
\hline Renal hypoplasia & 1 & Present at latest visit \\
\hline Drug induced & 1 & \\
\hline Lobenzarit disodium & 1 & Improved after drug treatment stopped \\
\hline \multicolumn{3}{|c|}{ During observation period $(\mathrm{n}=12)$} \\
\hline Drug induced & 9 & \\
\hline D-Penicillamine & 2 & $\begin{array}{l}\text { Improved after steroid treatment and drug } \\
\text { treatment stopped }\end{array}$ \\
\hline Diclofenac $\mathrm{Na}$ & 3 & Improved after drug treatment stopped \\
\hline $\mathrm{ACE}^{\star}$ inhibitor & 1 & Present at latest visit \\
\hline Diuretics & 3 & Present at latest visit \\
\hline $\begin{array}{l}\text { Diuretcs } \\
\text { Dehydration? }\end{array}$ & 2 & Appeared repeatedly during summer season \\
\hline Unknown & 1 & Present at latest visit \\
\hline
\end{tabular}

drug. As shown in table 4, the occurrence was the highest for D-penicillamine followed by gold thiomalate and bucillamine, a sulphydryl compound DMARD widely used in Japan. ${ }^{1}$ Auranofin and sulfasalazine induced PP occurred less frequently, whereas methotrexate did not cause PP in any of the patients. Among the NSAIDs, only sodium diclofenac caused $\mathrm{PP}$ in two patients.

PP appeared 2-39 months (mean 12.6, median 6) after the initiation of the drug. PP disappeared 1-24 months (mean 5.5, median 2.5) after the drug was stopped, except for two patients who were still using the drug at the last clinic visit or had stopped three months before the last visit. Proteinuria was associated with persistent haematuria in eight patients. In the two other patients treated with D-penicillamine, serum $\mathrm{Cr}$ was raised and a renal biopsy performed in one of the patients disclosed the presence of crescentic glomerulonephritis. This patient was treated aggressively with prednisolone, cyclophosphamide, and warfarin, which successfully reduced the level of $\mathrm{Cr}$ from $407 \mu \mathrm{mol} / 1(4.6 \mathrm{mg} / \mathrm{dl})$ to 150 $\mu \mathrm{mol} / 1(1.7 \mathrm{mg} / \mathrm{dl})$. Except for these two cases the serum $\mathrm{Cr}$ did not increase in any of the the serum $\mathrm{Cr}$ did not increase in any of the
patients with proteinuria induced by DMARDs.

On the other hand, the patient in whom PP was caused by sodium diclofenac twice showed a rise of $\mathrm{Cr}$.

RISK FACTORS FOR DRUG INDUCED PP

Patients with and without PP were compared to identify the risk factors associated with drug induced PP. As indicated in table 5, the CRP and ESR at entry and the percentage of patients aged over 50 at entry were significantly
higher in patients with PP than in those higher in patients with PP than in those
without PP. Patients with PP tended to show without PP. Patients with PP tended to show
persistent haematuria (PH) more often than those without PP (table 5). Neither the percentage of patients with haematuria at entry nor the number of DMARDs used during the observation period differed significantly between the two groups.

CAUSES AND COURSE OF RAISED CREATININE

Table 6 shows the number of patients with $\mathrm{RCr}$ either at entry or during the observation period. At entry, only two patients had RCr. The causes of RCr were lobenzarit disodium, ${ }^{17}$ a DMARD used in Japan, and congenital renal hypoplasia. During the observation period, 12 patients had $\mathrm{RCr}$ and although a drug was considered to be the cause in nine of them, DMARD induced RCr was found in only two patients.

HAEMATURIA

Table 7 compares the age and drug history of patients with and without haematuria at entry. Older people $(\geqslant 50)$ had a significantly higher incidence of haematuria. The incidence of haematuria at entry did not differ between patients who had been treated with NSAIDs or DMARDs, or both, before entry and those who had received no drug treatment. This suggested that neither the use of NSAIDs nor that of DMARDs increased the risk of haematuria. Similarly, NSAIDs and/or DMARDs used in he patients at the appearance of $\mathrm{PH}$ during the observation period were various, and no specific drugs were found to be definitively associated with $\mathrm{PH}$ (data not shown).

Because our data did not support the notion that drugs were related to haematuria, we then investigated whether the haematuria was associated with the activity of RA. Of 43 patients who exhibited PH during the study (table 2), those patients with PP (n=9) or RCr $(n=3)$ were excluded because most PP and RCr was caused by drugs. In addition, one patient with a bladder tumour was excluded. Those who had $\mathrm{PH}$ at entry $(\mathrm{n}=11)$ were also excluded because the activity of their RA at the time of the first appearance of $\mathrm{PH}$ was unknown. The CRP of the remaining 19 patients at the time 
Table 7 Occurrence of haematuria at entry in the study patients

\begin{tabular}{|c|c|c|c|c|}
\hline Classified by & $\begin{array}{l}\text { No of } \\
\text { patients } \\
(n=235)\end{array}$ & $\begin{array}{l}\text { No of patients with } \\
\text { haematuria }(n=40)\end{array}$ & $\begin{array}{l}\text { Occurrence of } \\
\text { haematuria (\%) }\end{array}$ & $p$ Value \\
\hline \multicolumn{5}{|l|}{ Age } \\
\hline & 40 & 4 & 10.0 & \\
\hline $40-49$ & 71 & 9 & 12.7 & $0.05^{\star}$ \\
\hline $50-59$ & 79 & 16 & 20.3 & \\
\hline$\geqslant 60$ & 45 & 11 & 24.4 & \\
\hline \multicolumn{5}{|l|}{ Drug used before the entry } \\
\hline NSAID $\ddagger$ alone & 113 & 20 & 17.7 & \\
\hline NSAID + DMARD $\ddagger$ & 27 & 4 & 14.8 & \\
\hline DMARD alone & 5 & 2 & 40.0 & \\
\hline No drug & 87 & 13 & 15.9 & NS† \\
\hline Unknown & 3 & 1 & & \\
\hline
\end{tabular}

${ }^{\star}$ Comparison between patients under 50 and those aged 50 or more.
†Comparison between patients not treated with drug and those treated with an NSAID alone or †Comparison between patients not treated
those treated with an NSAID + DMARD.

NSAID = non-steroidal anti-inflammatory drug; DMARD = disease modifying antirheumatic drug; NS = not significant. Table 8 Changes in C reactive protein (CRP) levels of the patients with isolated persistent
haematuria (PH). Data are mean (SD)

\begin{tabular}{llc}
\hline & $\begin{array}{l}\text { Patients with } \\
\text { disappeared PH }\end{array}$ & $\begin{array}{c}\text { Patients with } \\
\text { lasting PH }\end{array}$ \\
\hline Number of patients & 12 & 7 \\
CRP at entry $(\mathrm{mg} / \mathrm{l})$ & $13.2(12.8)$ & $19.6(26.1)$ \\
$\mathrm{CRP}$ at the time when $\mathrm{PH}$ developed $(\mathrm{mg} / \mathrm{l})$ & $18.8(19.7)^{\star}$ & $12.9(16.8)$ \\
$\mathrm{CRP}$ at the time when $\mathrm{PH}$ disappeared or at last visit $(\mathrm{mg} / \mathrm{l})$ & $3.9(3.8)^{\star} \dagger$ & $18.0(18.1) \dagger$ \\
\hline${ }^{*} \mathrm{p}=0.02$ by Wilcoxon test. & &
\end{tabular}

$\mathrm{p}=0.02$ by Wilcoxon test.

when isolated PH developed did not differ sig-

when isolated $\mathrm{PH}$ developed did not differ significantly from the CRP of patients without
haematuria $(n=136)$. Of these 19 patients, PH haematuria $(n=136)$. Of these 19 patients, $\mathrm{PH}$
eventually resolved in 12 patients and lasted eventually resolved in 12 patients and lasted CRP of the 19 patients at three points-at entry, at the time when $\mathrm{PH}$ developed, and when PH disappeared or at their last visit when $P$ dis 8). Although no difference was evident between the CRP at entry and the CRP at the
time when PH developed, there was a significant difference in 12 patients between the CRP at the time when $\mathrm{PH}$ developed and when $\mathrm{PH}$ disappeared. In contrast, the final CRP of the seven patients with lasting $\mathrm{PH}$ was not significantly different from the CRP at the point when PH developed. Lastly, the CRP of the 12 patients at the time of the disappearance of $\mathrm{PH}$ was significantly lower than the final CRP of the seven patients with lasting $\mathrm{PH}$, suggesting that isolated haematuria was associated with the disease activity of RA.

Discussion

The advantage of performing this kind of study in patients with early RA is that there is a low incidence of pre-existing renal damage or disease. Indeed, at entry into our study only two of the 235 patients enrolled had renal dysfunction and none of the patients exhibited proteinuria.

Drug induced proteinuria and renal dysfunction occurred in $1.7 \%$ and $1.5 \%$ of patients with early RA per year respectively. These values were lower than those reported in previous studies. ${ }^{18} 19$ This difference may be secondary to the fact that the doses of DMARDs we used were lower than those used in previous studies. For example, our standard dose of D-penicillamine is $100-200 \mathrm{mg} /$ day and that of gold thiomalate is $10-50 \mathrm{mg} / \mathrm{month}$.
The outcome of patients with DMARD induced nephropathy was generally good, except for the two patients who had received D-penicillamine and developed crescentic glomerulonephritis. Similar cases have been reported previously. ${ }^{21}$ Because crescentic reported previously. ${ }^{21}$ Because crescentic unlike AA amyloidosis, responds to steroid treatment the distinction between the two conditions is clinically important. Moreover, in our study D-penicillamine was associated with the highest occurrence of proteinuria followed by gold thiomalate and bucillamine. Therefore, from the viewpoint of renal toxicity, D-penicillamine is the DMARD that should be used with greatest care. No PP was seen in the patients who had taken methotrexate. Although the nephrotoxicity of sulfasalazine is unclear, ${ }^{22}$ the clinical course of our patient strongly suggested that this drug plays a part in the development of renal damage. Interestingly, in two patients the cause of proteinuria seemed to be sodium diclofenac, though NSAIDs are reported only rarely to cause proteinuria. ${ }^{23}$

In our study, haematuria was associated with drug induced PP more often than found in a previous report, ${ }^{24}$ though haematuria at entry was not found to be a risk factor for drug induced PP. Our data showed that a raised CRP and ESR at enrolment and age over 50 were risk factors for drug induced PP. The mechanism(s) by which more active inflammation render patients susceptible to the development of drug induced proteinuria remain(s) to be elucidated.

Although DMARDs were the responsible drugs in most cases of drug induced proteinuria, $\mathrm{RCr}$ was caused by a variety of drugs, including NSAIDs, diuretics, and angiotensin converting enzyme inhibitors. However, in patients with RCr caused by diuretics or dehydration during summer months, NSAIDs were likely to play a part in their renal dysfunction because acute renal failure may be induced by the use of NSAIDs in patients who rely upon prostaglandins to maintain their renal blood prostaglandins to maintain their renal blood ow. ${ }^{25}{ }^{26}$ It should be noted that renal dysfunction may actually occur more often than was found in this study because the value of $\mathrm{Cr}$ may underestimate renal function in patients with RA with the significant muscle atrophy that can be seen in these patients. ${ }^{27}$

There is controversy about the causes of haematuria seen in patients with RA. Thus some authors have indicated an association between haematuria and drugs, ${ }^{28}$ whereas others have not found such an association. ${ }^{29}{ }^{30}$ Renal papillary necrosis induced by NSAIDs is unlikely to be a cause of haematuria in this tudy because no patient with haematuria cor Thin Thin basement membrane disease has been reported to be related to gold thiomalate and to haematuria. ${ }^{32}$ However, haematuria in our study showed no relation to any drugs. Korpela et al concluded that there was no difference in the prevalence of isolated haematuria between patients with RA and control subjects, ${ }^{12}$ which is in marked contrast with the reported findings 
of several other groups. ${ }^{28} 3032$ Mesangioproliferative glomerulonephritis can be caused by RA itself, ${ }^{33}$ and this is supported by our data because isolated haematuria improved when the disease activity of RA diminished, as indicated by a fall in CRP levels. It may be the case that cytokines, such as interleukin 6 , which is known to be raised in RA, ${ }^{3536}$ may induce the proliferation of mesangial cells as has been shown in animal models of renal disease ${ }^{37}{ }^{38}$ Of course, other factors apart from the activity of RA must play a part in the development of haematuria because many patients with higher CRP levels did not develop haematuria.

In conclusion, proteinuria, haematuria, and renal dysfunction are found in a high percentage of patients with early RA. Proteinuria in patients with early RA was mostly induced by DMARDs, whereas various drugs caused renal dysfunction. Most of these drug induced abnormalities disappeared when the offending drug was stopped. In contrast, isolated haema-
turia was not caused by drugs but seemed to be turia was not caused by drugs but seemed to be patients.

1 Boers M, Croonen AM, Dijkmans BAC, Breedveld FC, Eulderink F, Cats A, et al. Renal findings in rheumatoid arthritis: clinical aspects of 132 necropsies. Ann Rheum Dis

2 Calvo-Alén J, De Cos MA, Rodríguez-Valverde V, Escallada 年

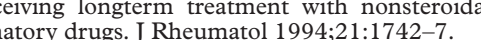

3 Boers M, Dijkmans BAC, Breedveld FC, Camps JAJ, Chan PC, van Brummelen P, et al. Subclinical renal dysfunction in rheumatoid arthritis. Arthritis Rheum 1990;33:95-101. Sorensen AWS. The kidney function in patients with rhe disease. Acta Rheumatol Scand 1964:10:11-28. Dieppe PA, Doyle DV, Burry HC, Tucker SM. Renal disease in rheumatoid arthritis. BMy 197, 作 toid arthritis patients with hematuria or proteinuria. Nephron 1986;42:224-30. ity and causes of death in patients with rheumatoid arthrtis. BMJ 1985;290:1797-9.
tis

8 Suzuki A, Ohosone Y, Obana M, Mita S, Matsuoka Y, Irimajiri S, et al. Cause of death in 81 autopsied patien Hall CL, Jawad S, Harrison PR, MacKenzie JC, Bacon PA, Klouda PT, et al. Natural course of penicillamin 296:1083-6.

10 Hall CL, Fothergill NJ, Blackwell MM, Harrison PR, MacKenzie JC, Maclver AG. The natural course of gold
nephropathy: long term study of 21 patients. BMJ nephropathy: long term study of 21 patients. BM
1987;295:745-8.

1 Hordon LD, Sellars L, Morley AR, Wilkinson R, Thompson
M, Griffiths ID. Haematuria in rheumatoid arthritis: an association with mesangial glomerulonephritis. Ann association with mesangial glomerulonephritis. An
Rheum Dis 1984;43:440-3.

2 Korpela M, Mustonen J, Heikkinen A, Helin H, Pasternack A. Isolated microscopic hematuria in patients wit controls. A population based study. J Rheumatol 1995;2 Gertz 31 A, Kyle RA Secondary systemic amyloidosis: 3 Gertz MA, Kyle RA. Secondary systemic amyloidosis
response and survival in 64 patients. Medicine (Baltimore)
1991;70:246-56.
14 Ropes MW, Bennett GA, Cobb S, Jacox R, Jessar RA. 1958 revision of diagnostic criteria

5 Arnett FC, Edworthy SM, Bloch DA, McShane DJ, Fries $\mathrm{JF}$, Cooper NS, et al. The American Rheumatism Associatoid arthritis. Arthritis Rheum 1988;31:315-24.

6 Yoshida A, Morozumi K, Suganuma T, Sugito K, Ikeda M, Oikawa T, et al. Clinicopathological findings of

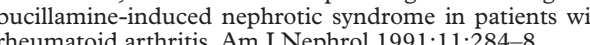

7 Sato $T$, Ozawa $T$, Ueno $M$, Kikuchi $M$, Nakano $M$, Takahashi C, et al. A study of renal injury induced by
lobenzarit disodium (in Japanese). Jin to Toseki 1990;28 lobenzarit disodium (in Japanese). Jin to Toseki 1990;28.

toid $\mathrm{BE}$, Woodrow DF, Scott JT. Proteinuria in rheumatoid arthritis: d

9 Boers M. Renal disorders in rheumatoid arthritis. Semin

gressive glomerulonephritis in a patient with rheumatoi arthritis during treatment with high-dosage 1 Banfi G, Imbasciati E, Guerra L, Mihatsch MJ, Ponticelli C Extracapillary glomerulonephritis with necrotizing vascultis in D-penicillamine-treated rheumatoid arthritis. Neph-

Barbour VM, Williams PE. Nephrotic sy
with sulphasalazine. BMJ 1990;301:818.

Pirson Y, van Ypersele de Strihou C. Renal side effects of

Helin HJ, Korpel biopsy findings and clinicopathologic correlations in rhe Uatid arthiss. Ar thr

ment associated with non-steroidal anti-inflammatory drugs. Ann Rheum Dis 1987;46:233-6. 6 Kimberly RP, Gill JR, Bowden RE, Keisser HR, Plotz PH on renal function in lupus erythematosus. Ann Intern Med 1978;89:336-41.

Nived $\mathrm{O}$, Sturfelet $\mathrm{G}$, Westling $\mathrm{H}$, White $\mathrm{T}$. Is serum creat-

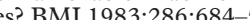

8 Israel AR, Susin M, Vaughan ED. Microhematuria associ-
ated with gold therapy: evaluation and management. J Urol

Mustonen J, Pasternack A, Helin H. Mesangi follow-up and relation to antirheumatic therapy. Nephron

Leonard PA, Bienz SR, Clegg DO, Ward JR. Hematuria in
patients with rheumatoid arthritis receiving gold and d-penicillamine. J Rheumatol 1987;14:55-9.

31 Lourie SH, Denman SJ, Schroeder ET. Association of renal Rheum 1977;20:917-21.

2 Saito T, Nishi R, Karasawa H, In H, Hayashi H, Ueno M, et al. An ultrastructural study of glomerular basement mem-
brane in rheumatoid arthritis patients with urinary abnormalities. Clin Nephrol 1995;43:360-7. 33 Ramirez G, Lambert R, Bloomer HA. Ren rheumatoid arthritis. Nephron 1981;2:124-6. Wase tory in 158 Japanese patients with rheumatoid arthritis.

Clin Nephrol 1998;50:154-60.
5 Hirano T, Matsuda T, Turner M, Miyasaka N, Buchan G Tang B, Excessive production of interleukin $6 / \mathrm{B}$ cell nol 1988;18:1797-801.

6 Houssiau FA, Devogelaer J-P, van Damme J, Nagant de Dith inflammatory arthritides. Arthritis Rheum 1988;31:784-8. 37 Horii Y, Muraguchi A, Iwano M, Matsuda T, Hirayama proliferative glomerulonephritis. J Immunol 1989;143. 3949-55.

38 Suematsu S, Matsuda T, Aozasa K, Akira S, Nakano N, Ohno S, et al. IgG1 plasmacytosis in interleukin
transgenic mice. Proc Natl Acad Sci USA 1989;86:7547- 